\title{
Diagnóstico sócio-parasito-sanitário da cidade de Nova Olinda do Norte - Amazonas
}

\author{
Marcelo Montoril Filho (") \\ José João Ferraroni (**) \\ Dione de Andrade Alecrim Montoril (*)
}

\begin{abstract}
Resumo
Os autores fazem um estudo social, sanitário e pa rasitológico da cidade de Nova Olinda do Norte, Amazonas-Brasil, dando ênfase aos tipos de habitações, destino dos dejetos, tipos de sanitários, fonte de água para o consumo e tratamento da mesma, assim como a prevalência dos helmintos e protozoários. Discutem os resultados comparando-os com resultados encontrados em outras cidades da Amazônia.
\end{abstract}

\section{INTRODUÇÃo}

O número de pacientes portadores de parasitoses intestinais é altíssimo nas cidades do interior do Estado do Amazonas. Qualquer indivíduo ligado ao setor de saúde exercendo atividades em áreas do interior, é conhecedor profundo deste fato e que, apesar de ser raro um exame coproparasitológico revelar um resultado negativo, quando positivo, muitas vezes revela infestação associada a mais de um parasita. Mesmo em relação a outras patologias, os diversos fatores ligados a recusa de comparecer ao hospital ou procurar tratamento médico precocemente, fazem com que a chegada do paciente ao médico só aconteça após experimentar os mais variados tipos de medicamentos, receitados por curiosos, ou pelos próprios pacientes, que na grande maioria das vezes prejudicam o tratamento adequado e até mesmo mascaram a patologia inicial.

As precárias condições de saneamento das áreas urbanizadas aliadas ao baixo nível sócioeconômico e, conseqüentemente, a ignorância, o baixo índice de alfabetizados e a falta de orientação sanitária da população são fatores decisivos na determinação do alto percentual de infestados. As condições climáticas, princi- palmente na época das cheias, completam o quadro dramático na disseminação das formas infestantes dos parasitas. Apesar de tão relevante problema, existem poucos dados comprovando a incidência das parasitoses na capital e no interıor e também pouca literatura sobre o assunto no Estado do Amazonas.

Acima de tudo sabe-se que as infecçōes gastro-intestinais são responsáveis por eleva. dos índices de mortalidade em crianças em toda a região Amazônica e que os helmintos e protozoários desempenham importantes papeis no agravamento destes índices. Resolvemos, então, fazer um levantamento das condições sócio-sanitárias das unidades residenciais e proceder a exames parasitológicos da população para verificar o comportamento das parasitoses na Cidade de Nova Olinda do Norte.

\section{MATERIAIS E MÉTODOS}

A cidade de Nova Olinda do Norte, fundada em 1954, quando era pesquisado petróleo pela PETROBRAS, localiza-se a margem direita do rio Madeira, afluente da margem direita do rio Amazonas. Dista aproximadamente $140 \mathrm{~km}$ em linha reta da Cidade de Manaus (mapa anexo) e está situada em terra firme. Contava com 531 residências e 2871 habitantes, na época da realização da pesquisa.

Quinhentos e vinte e oito das 531 residências da cidade foram visitadas, verificando em cada uma o número de pessoas residentes; a fonte de água consumida pelos familiares. principalmente a potável; o tipo de habitação conforme o material usado na construção, assoalho, parede e cobertura; o tipo de fossa usada pela família, distância dessas fossas da casa e do rio e profundidade das mesmas.

(*) - Secretaria de Saúde do Estado do Amazonas.

(*) - Instituto Nacional de Pesquisas da Amazônia, Manaus. 


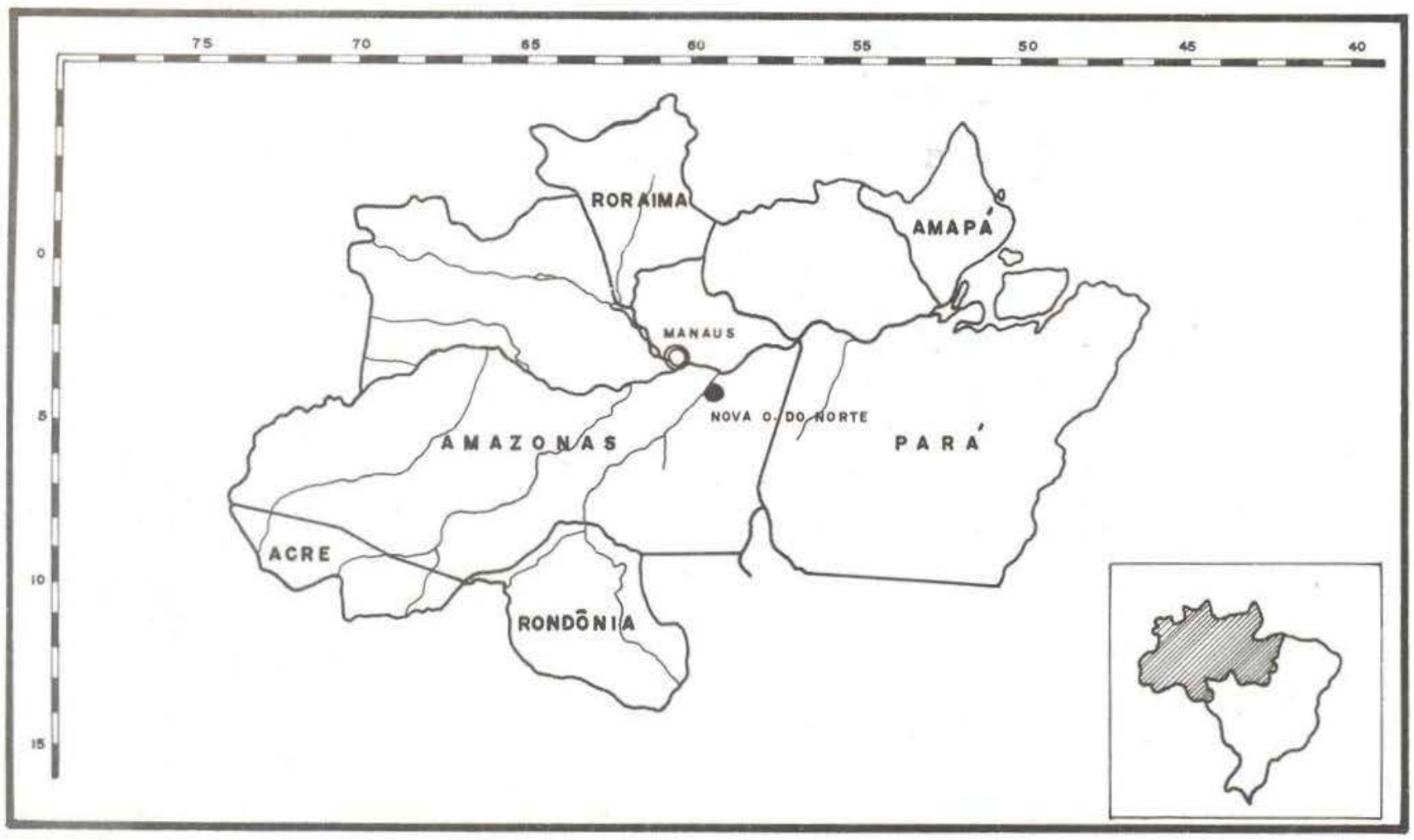

Mapa da localizaçăo geográfica da cidade de Nova Olinda do Norte

Foram efetuados 1500 exames coproparasitológicos, utilizando o método de Faust (1939) e método direto. Os exames eram realizados na Unidade Hospitalar na cidade. No momento da visita às residências, destribuia-se um re. cipiente apropriado (latinha) para coleta das fezes e os habitantes eram convidados a levar o material ao hospital. A pesquisa foi realizada durante 18 meses, de dezembro de 1974 a maio de 1976.

\section{RESULTADOS}

\section{TIPOS DE HABITAÇÃO}

Das 528 residências visitadas, $286(54,2 \%)$ eram de madeira com cobertura de telha; 164 $(31,0 \%)$ eram de madeira com cobertura de palha (folha de palmeira); $56(10,6 \%)$ eram construídas unicamente de palha; $13(2,5 \%)$ eram construídas de alvenaria e $9(1,7 \%)$ eram construídas de madeira, com piso de alvenaria (tabela e figura 1).

\section{DESTINO DOS DEJETOS}

Das residências pesquisadas, $328(62,1 \%)$ possuiam como fossa um buraco no chäo, cuja profundidade variava em torno de um metro. sempre próximo à residência, às vezes protegido por quatro paredes de madeira ou uma pequena casinha de folhas de palmeiras: 144 $(27,3 \%)$ não tinham fossas; $42(8,0 \%)$ possuiam fossa biológica e $14(2,7 \%)$ estavam desabitadas, não sendo possivel obter dados (tabela e figura 2).

\section{TIPO DE ASSOALHO NO INTERIOR DO SANITÁRIO}

Foram visitados todos os 370 sanitários existentes na cidade, dos quais $315(85,1 \%)$ tinham assoalho de madeira sobre $\alpha$ buraco da fossa; $46(12,4 \%)$ possuiam assoalho de cimento e vaso sanitário que nem sempre desembocava na fossa biológica e $9(2,4 \%)$ possuiam assoalho de cimento sem vaso sanitário (tabela e figura 3). 


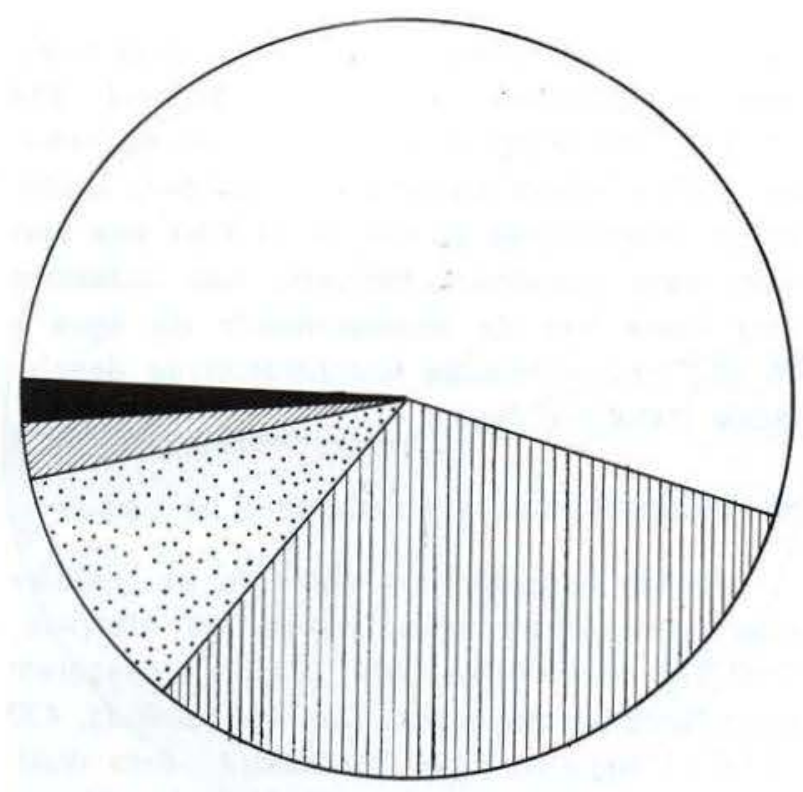

$54,2 \%$ Casa de madeira coberta com telha

$31.0 \%$ Casa de madeira coberta com paina

$\because \because: \because 10,6 \%$ Casa de palno

$2,5 \%$ Casa de Alvenaria

1, 7 \% Casa de madeira com piso de madeiro

Fig. 1 - Tipos de habitaçăo existentes na cidade de Nova Olinda do Norte - 1976

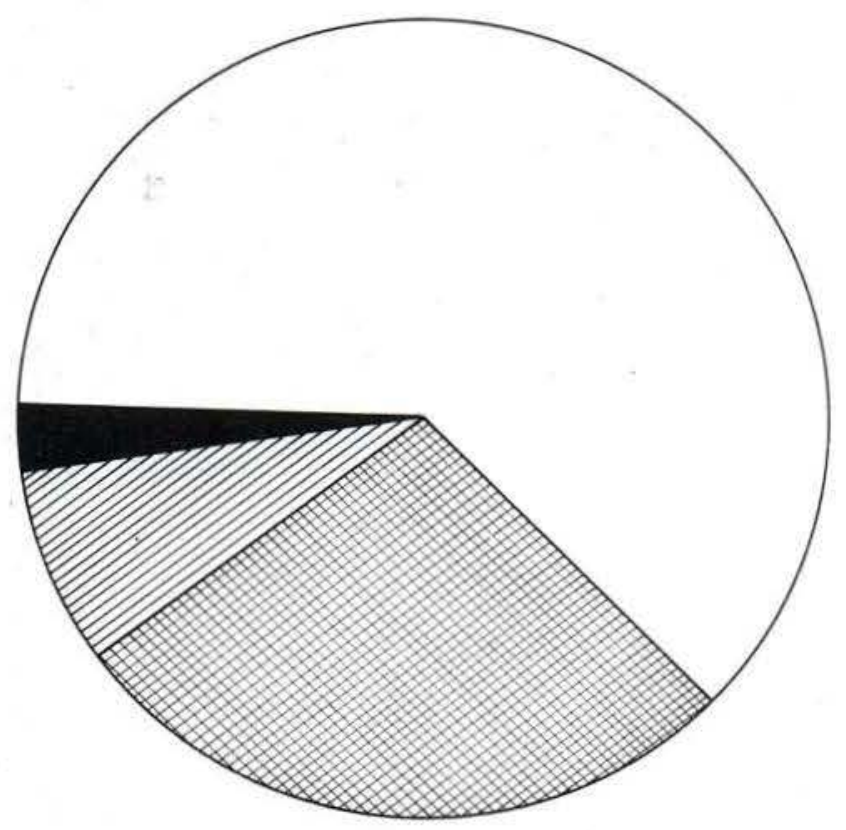

$62.1 \%$ Buraco simples no solo

$27.2 \%$ Ausência de qualquer tipo de fossa

$8,0 \%$ Fossa biológica

$2,7 \%$ Dados nāo computados

Fig. 2 - Tipos de fossa usados pela população da cidade de Nova Olinda do Norte - 1976.

TABELA N $\circ 1$ - Tipos de habitaçăo usadas pelos habitantes de Nova Olinda do Norte, segundo a maneira de de construçäo - 1976

\begin{tabular}{|c|c|c|c|c|c|c|}
\hline $\begin{array}{l}\text { Tipo de } \\
\text { construçäo }\end{array}$ & $\begin{array}{l}\text { Madeira co- } \\
\text { berta c/telha }\end{array}$ & $\begin{array}{l}\text { Madeira co- } \\
\text { berta c/palha }\end{array}$ & Palha & Alvenaria & $\begin{array}{l}\text { M. com piso } \\
\text { de alvenaria }\end{array}$ & Total \\
\hline $\begin{array}{l}\text { N. }{ }^{\circ} \text { de } \\
\text { habitaçōes }\end{array}$ & 286 & 164 & 56 & 13 & 9 & 528 \\
\hline$\%$ & 54,2 & 31,0 & 10,6 & 2,5 & 1,7 & 100,0 \\
\hline
\end{tabular}

TABELA N. 2 - Tipos de fossas usadas pela população de Nova Olinda do Norte - 1976

\begin{tabular}{|c|c|c|c|c|c|}
\hline $\begin{array}{c}\text { Tipos de } \\
\text { fossa }\end{array}$ & $\begin{array}{c}\text { Buraco no } \\
\text { solo }\end{array}$ & Biológica & $\begin{array}{l}\text { Ausência } \\
\text { de fossa }\end{array}$ & $\begin{array}{l}\text { Dados näo } \\
\text { compuatdos }\end{array}$ & Total \\
\hline $\begin{array}{l}\text { N. o de } \\
\text { fossas }\end{array}$ & 328 & 42 & 144 & 14 & 528 \\
\hline$\%$ & 62,1 & 8,0 & 27,2 & 2,7 & 100,0 \\
\hline
\end{tabular}




\section{FONTE DE ÁGUA PARA O CONSUMO}

Das 528 residências visitadas, $237(44,8 \%)$ delas possuiam água encanada (foi considera-

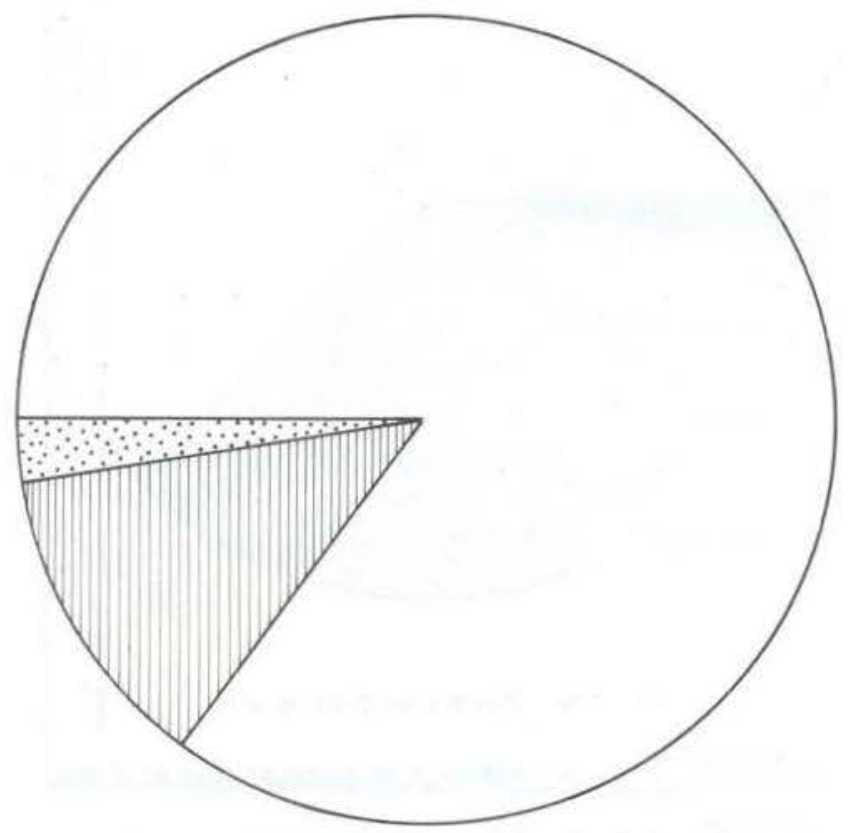

$\square 85,2 \%$ Assoulho detábua

[IIIIII $12,4 \%$ Assoalho de cimento c/descarga

$2 \because \because 2,4 \%$ Assoalho de cimento s/descarga

Fig. 3 - Tipos de assoalho dos sanitários de 370 residências da cidade de Nova Olinda do Norte - 1976. do existir água encanada quando duas ou mais famílias utilizavam a mesma torneira): 218 $(41,3 \%)$ retiravam água de poço ou cacimba: $49(9,3 \%)$ faziam a coleta da água, para o consumo, diretamente do rio; $10(1,9 \%)$ que serviam para comércio também, não possuiam uma fonte fixa de abastecimento de água e $14(2,7 \%)$ residências encontravam-se desabitadas (tabela e figura 4).

TRATAMENTO DADO À ÁGUA ANTES DO USO

Foram considerados somente as residên. cias que apresentavam moradores efetivos. Das 528 residências, $494(93,6 \%)$ possuiam moradores permanentes. Das 494 famílias, 430 $(87,0 \%)$ usavam água "in natura" sem qualquer tratamento prévio; $46(9,4 \%)$ usavam água filtrada; $12(2,4 \%)$ usavam água fervida e filtrada e $6(1,2 \%)$ usavam água somente fervida (tabela e figura 5 ).

\section{PREVALENCIA DOS HELMINTOS}

Dos 1500 exames coproparasitológicos realizados, $1258(83,9 \%)$ foram positivos para helmintos, na seguinte distribuição: 987 $(65,8 \%)$ foram positivos para Ascaris lumbricoides; $750(50,0 \%)$ apresentaram positividade para Trichocephalus trichiurus; 479 (31,9\%) foram positivos para Ancilostomídeos; 40

TABELA N.॰ 3 - Tipos de assoalho dos sanitários de 370 residências na cidade de Nova Olinda do Norte - 1976

\begin{tabular}{l|c|c|c|c}
\multicolumn{1}{c|}{$\begin{array}{c}\text { Tipos de } \\
\text { assoalho }\end{array}$} & Tábuas & $\begin{array}{c}\text { Cimento } c / v a s o \\
\text { sanitário }\end{array}$ & Cimento & To ta l \\
\hline $\begin{array}{l}\text { N.O de } \\
\text { sanitários }\end{array}$ & 315 & 46 & 9 & 370, \\
& 85,2 & 12,4 & 2,4 & 100,0 \\
\hline
\end{tabular}

IABELA N. 04 - Fonte de água para o consumo de 528 familias residentes na cidade de Nova Olinda do Norte - 1976

\begin{tabular}{l|c|c|c|c|c|c}
\hline $\begin{array}{c}\text { Tipo de } \\
\text { fonte de água }\end{array}$ & Encanada & $\begin{array}{c}\text { Poço ou } \\
\text { cacimba }\end{array}$ & Rio & $\begin{array}{c}\text { Várias } \\
\text { fontes }\end{array}$ & $\begin{array}{c}\text { Dados năo } \\
\text { computados }\end{array}$ & To t a I \\
\hline $\begin{array}{l}\text { N. O de } \\
\text { residências } \\
\%\end{array}$ & 237 & 218 & 49 & 10 & 14 & 528 \\
\hline
\end{tabular}




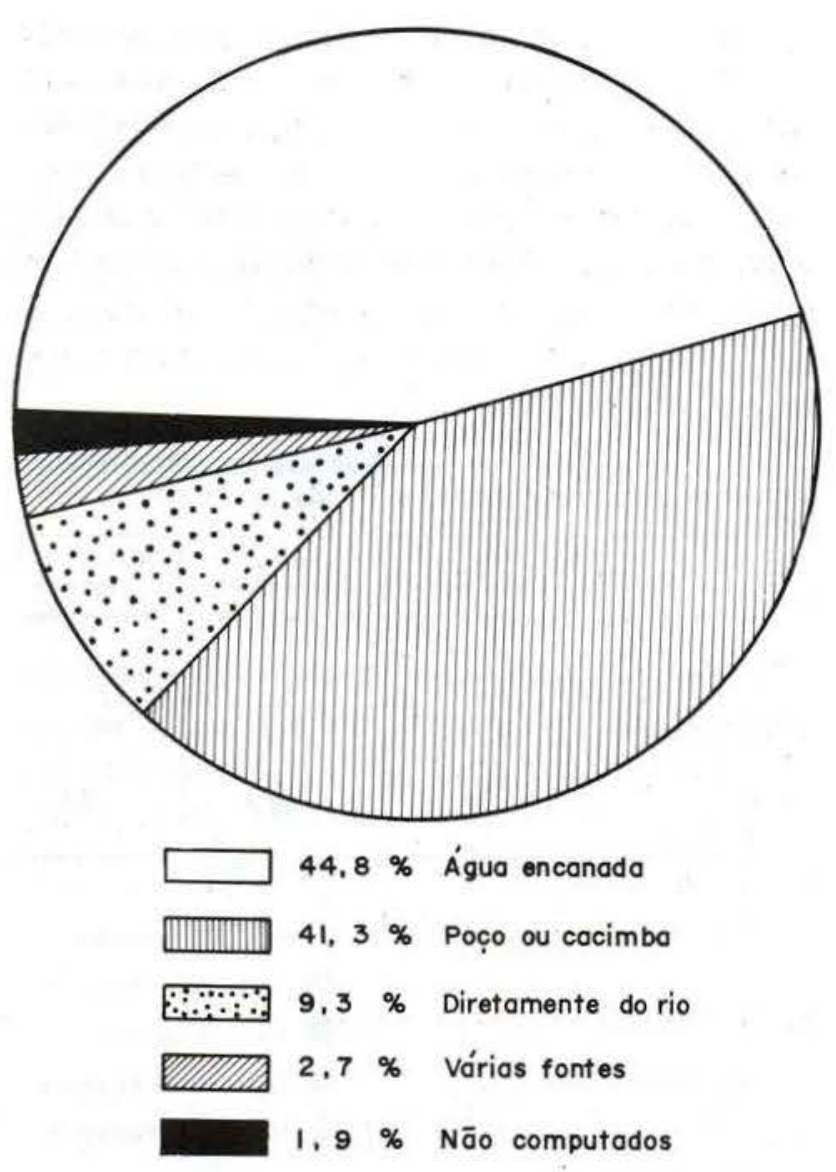

Fig. 4 - Fonte de água para o consumo em 528 familias residentes na cidade de Nova Olinda do Norte -1976 .

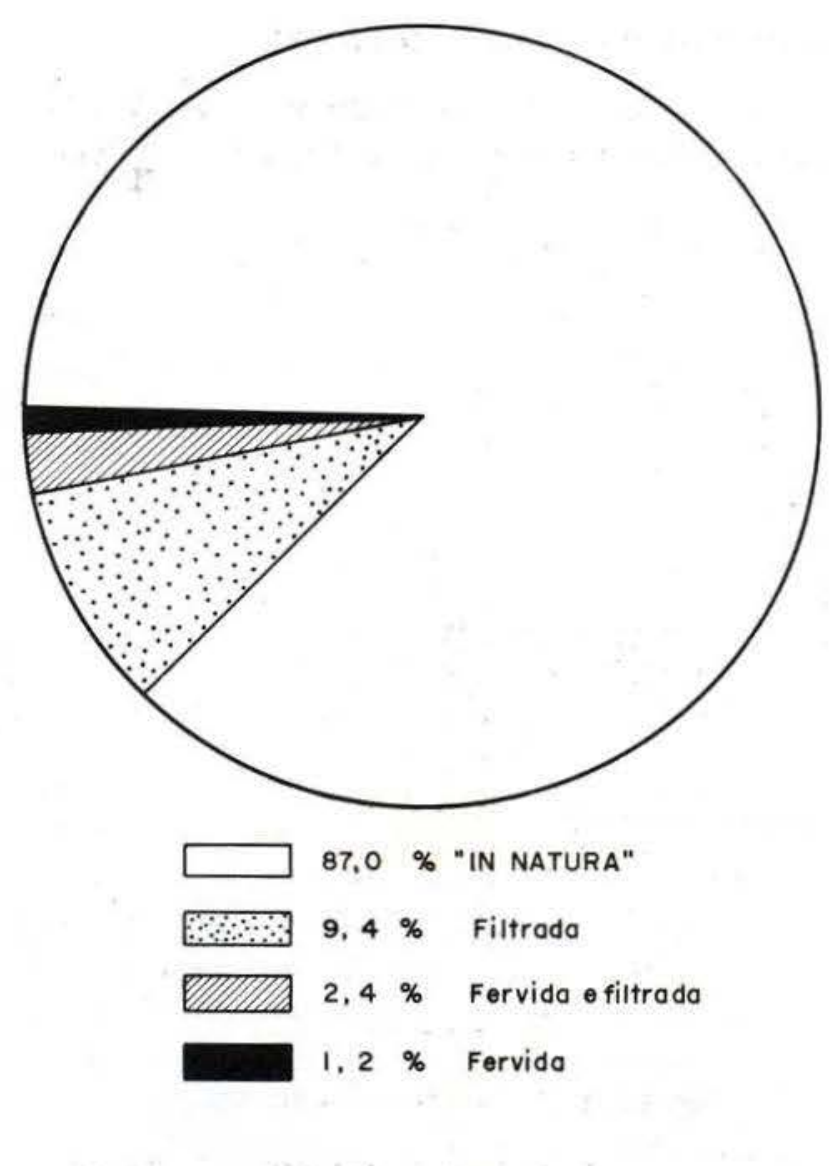

Fig. 5 - Tratamento da água e seu consumo nas 394 familias da cidade de Nova Olinda do Norte $-1976$.

TABELA N.॰ 5 - Tratamento da água para consumo das 394 familias da cidade de Nova Olinda do Norte - 1976

\begin{tabular}{c|c|c|c|c|c}
\hline $\begin{array}{c}\text { Tratamento } \\
\text { da água }\end{array}$ & "In Natura" & Filtrada & $\begin{array}{c}\text { Fervida e } \\
\text { filtrada }\end{array}$ & Fervida & Tot a I \\
\hline $\begin{array}{c}\text { N.० de } \\
\text { familias }\end{array} \%$ & 430 & 46 & 12 & 6 & 494 \\
\hline
\end{tabular}

TABELA N.०6 - Percentual de helmintos, por espécie, encontrados em 1.500 exames coproparasitológicos, reallzados na cidade de Nova Olinda do Norte - 1976

\begin{tabular}{l|c|c|c|c|c}
\hline \multicolumn{1}{c|}{$\begin{array}{c}\text { Helmintos } \\
\text { espécie }\end{array}$} & $\begin{array}{c}\text { A. lumbri- } \\
\text { coides }\end{array}$ & T. trichiurus & $\begin{array}{c}\text { Ancilosto- } \\
\text { mídeos }\end{array}$ & $\begin{array}{c}\text { S. sterco- } \\
\text { ralis }\end{array}$ & $\begin{array}{c}\text { E. vermicu- } \\
\text { laris . }\end{array}$ \\
\hline $\begin{array}{l}\text { N.o de exames } \\
\text { positivos }\end{array}$ & 987 & 750 & 479 & 40 & 27 \\
& 65,8 & 50,0 & 31,9 & 2,7 & 1,8 \\
\hline
\end{tabular}

Diagnóstico sócio-parasito-sanitário... 
$(2,7 \%)$ apresentaram-se positivos para Strongyloides stercoralis e $27(1,8 \%)$ foram positivos para Enterobius vermicularis (tabela $6 \mathrm{e}$ figura 7).

\section{PREVALÊNCIA DOS PROTOZOÁRIOS}

Des exames realizados $516(34,4 \%)$ foram positivos para protozoários, na seguinte ordem:

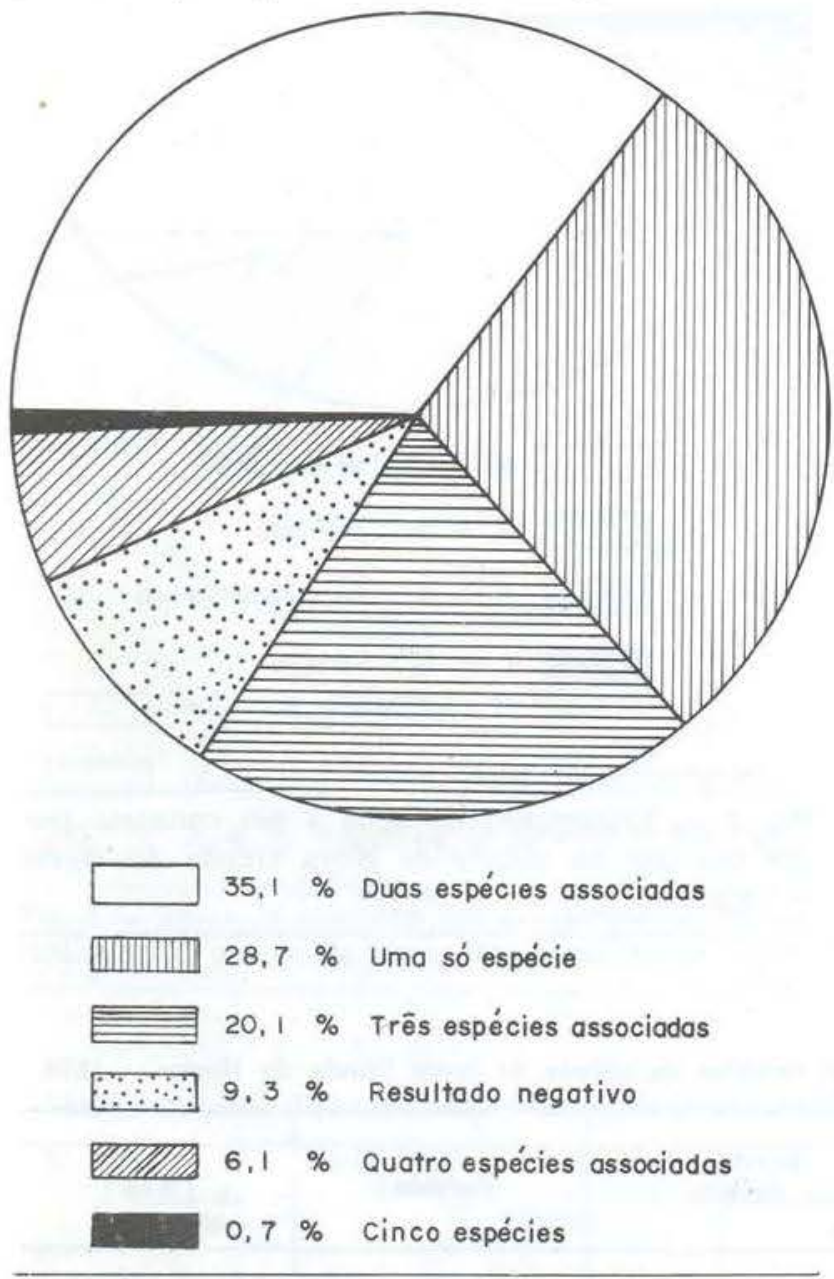

Fig. 6 - Infestaçõeõs associadas em um mesmo paciente nos 1500 exames coprológicos realizados nos habitantes da cidade de Nova Olinda do Norte.
$183(12,2 \%)$ foram positivos para Entamoeba histolytica; $151(10,1 \%)$ foram positivos para Entamoeba coli; $135(9,0 \%)$ foram positivos para Giardia lamblia; $41(2,7 \%)$ foram positivos para Endolimax nana e $6(0,4 \%)$ foram positivos para Chilomastik mesnili (tabela 7 e figura 8).

TABELA N.॰ 8 - Percentual relacionando helmintos e protozoários encontrados em 1500 exames coprológicos realizados na cidade de Nova Olinda do Norte - 1976

\begin{tabular}{c|c|c|c}
\hline $\begin{array}{c}\text { Grupo de } \\
\text { parasitos }\end{array}$ & $\begin{array}{c}\text { Helmintos } \\
\text { (ex. positivos) }\end{array}$ & $\begin{array}{c}\text { Protozoários } \\
\text { (ex. positivos) }\end{array}$ & $\begin{array}{c}\text { Exames } \\
\text { negativos }\end{array}$ \\
\hline N. de exames & 1258 & 516 & 140 \\
$\%$ & 83,8 & 31,1 & 9,4 \\
\hline
\end{tabular}

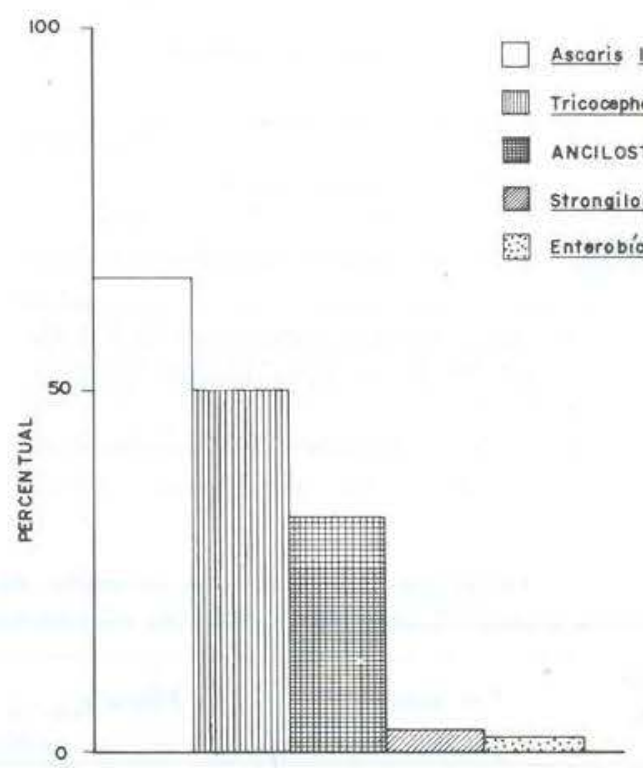

Fig. 7 - Percentuol de helmintos por espécie encontrados em 1500 exames coproparasitológicos realizados na cidade de Nova Olinda do Norte.

TABELA N. 7 - Percentual de protozoários, por espécie, encontrados em 1500 exames coprológicos, realizados na cidade de Nova Olinda do Norte - 1976

\begin{tabular}{c|c|c|c|c|c}
\hline $\begin{array}{c}\text { Protozóários } \\
\text { espécie }\end{array}$ & E. histolytica & E. coli & G. lamblia & E. nana & C. mesnill \\
\hline $\begin{array}{l}\text { N.o de exames } \\
\text { positivos }\end{array}$ & 183 & 151 & 135 & 41 & 6 \\
$\%$ & 12,2 & 10,1 & 9,0 & 2,7 & 0,4 \\
\hline
\end{tabular}


Do total de exames realizados $140(9,3 \%)$ aprésentaram resultados negativos. Verificouse ainda que $431(28,7 \%)$ dos pacientes eram parasitados por uma única espécie de parasita; $526(35,1 \%)$ eram parasitados por duas espé. cies de parasitas; $302(20,1 \%)$ eram parasitados por três espécies de parasitas; $91 \quad(6,1 \%)$ eram parasitados por quatro espécies e 10 $(0,7 \%)$ eram parasitados por cinco espécies de parasitas (tabela n. 9 e fig. 6).

\section{Discussão}

Nossos resultados apresentaram algumas variaçōes quando comparados com outros trabalhos realizados na Amazônia. Num estudo coproparasitológico realizado em Manaus (Pinheiro et al., 1976), verificou-se que $T$. trichiurus foi o que prevaleceu entre os helmintos,

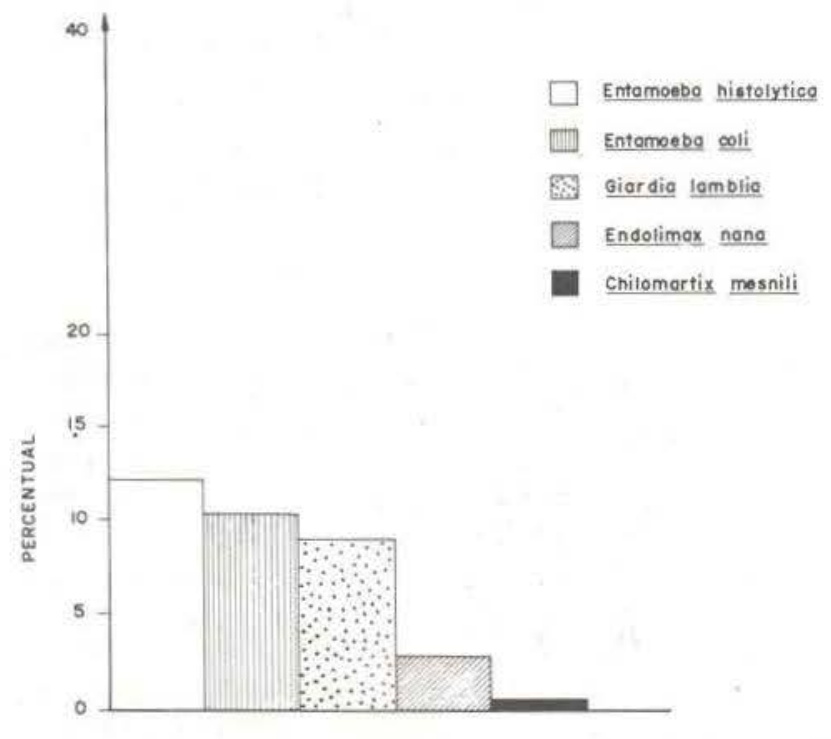

Fig. 8-Percentual de protozoários por espécie encontrados em 1500 exames coproparasitológicos realizados na cidade de Nova Olinda do Norte. em média de $72,25 \%$ e dentre os protozoários o maior índice foi representado pela Giardia lamblia $(17,67 \%)$ em média. Na cidade de Codajás (Moraes, 1959) encontrou o T. trichiurus numa percentagem de $88,20 \%$ e $E$. histolytica em $20,20 \%$. Num inquérito realizado por Costa (1947) em quatro cidades da Amazônia (Cametá, Abaetetuba, e Monte Alegre), foi encontrada a prevalência do Ascaris lumbricoides com $82,32 \%$ entre os helmintos e entre os protozoários o maior índice foi representado pela E. histolytica com $5,72 \%$. Em Belém, Causey (1947) encontrou $64,70 \%$ para o $A$. lumbrlcoides e $13,00 \%$ para $E$. histolytica e em Icoraí o mesmo autor encontrou $86,80 \%$ para o $A$. lumbricoides e $28,10 \%$ para a $E$. histolytica.

A região de Nova Olinda do Norte vem sendo assolada ultimamente por enchentes sucessivas, deixando em conseqüência, fome e miséria que se acentua de forma inexorável, principalmente no caboclo que migra de suas terras devastadas. Isto faz com que as novas residências ou casebres, tipo palhoças, construidas muito rapidamente, sem as mínimas condições sanitárias, aliadas a promiscuidade e ignorância, seja um foco de doenças, principalmente infecciosas e parasitárias. Juntamente com outros fatores, as dificuldades dos pacientes em procurar o médico com maior fre qüência, levam a uma maior morbidade. Quando pacientes comparecem para iniciar um tratamento quase sempre năo retornam para completá-lo, haja vista que em 1500 consultas realizadas, apenas $32(2,1 \%)$ retornaram nos 20 dias seguintes para o controle. Durante os 90 dias seguintes ao primeiro contato, apenas $57(3,8 \%)$ retornaram para o controle.

O município possui poucas fontes de renda própria, as quais se resumem a alguma ativi.

TABELA N.ค9 - Percentual, relacnonando o número de parasitas associados em um mesmo paciente, encontrados em 1500 exames coprológicos realizados na cidade de Nova Olinda do Norte - 1976

\begin{tabular}{c|c|c|c|c|c|c|c}
\hline $\begin{array}{c}\text { N.० de espécie } \\
\text { associados }\end{array}$ & $\begin{array}{c}\text { Uma } \\
\text { espécie }\end{array}$ & $\begin{array}{c}\text { Duas } \\
\text { espécies }\end{array}$ & $\begin{array}{c}\text { Três } \\
\text { espécies }\end{array}$ & $\begin{array}{c}\text { Quatro } \\
\text { espécies }\end{array}$ & $\begin{array}{c}\text { Cinco } \\
\text { espécies }\end{array}$ & Negativos & Tota I \\
\hline N.0 de exames & 431 & 526 & 302 & 91 & 10 & 140 & 1500 \\
$\%$ & 28,7 & 35,1 & 20,1 & 6,1 & 0,7 & 9,3 & 100,0 \\
\hline
\end{tabular}


dade do comércio, empregos nas repartiçōes públicas municipais e estaduais. A agricultura tem pouca representação econômica, assim como a pesca. Isto determina um baixo poder aquisitivo.

As dificuldades em se aplicar educação sanitária são imensas, considerando-se o baixo nível de escolaridade do povo do interior Ama. zônico e escasso material humano apto a dar tais informações. Torna-se difícil e quase impossível convencer a caboclo, que sempre tomou água do rio e diz sentir-se saudável, a ferver e filtrar a água antes de ingerí-la, para evitar problemas com saúde. A mesma coisa com relação a construção de fossa, quando ele sempre defecou a "ceu aberto" ou na água do rıo. aproveitando a correnteza. É difícil ele acreditar que um verme pode penetrar pela pele. Os profissionais de saúde, aliás raríssimos nessas áreas, pelo acúmulo de trabalho, pela falta de estímulos, gastam quase todo seu tempo, exclusivamente fazendo terapêutica curativa, mesmo sabendo eles que após 20 ou 30 dias o paciente estará reinfestado.

Não há saneamento básico. Grande parte da população $(27,2 \%)$ não usa fossa, quando ela existe é rústica e não devidamente construida.

Um buraco no solo representa a maioria dos coletores de dejetos $(62,1 \%)$. Verifica-se que, na perfuração da fossa, não houve a preocupação de saber a distância da cacimba, daí encontrarmos poços com distâncias menores de 4 metros das fossas. Outro fator importante é a profundidade das fossas, que raramente ultrapessa a um metro. Na época das cheias, uma parte da cidade é invadida pelas águas do rio, nos últimos três anos. Na rua principal onde o nivel das águas sobe para mais de um metro e meio, existem fossas feitas apenas de um buraco no solo $(62,1 \%)$, tendo como suporte para os pés apenas duas tábuas para. lelas. A água penetra nas fossas e o conteúdo delas transborda pela rua. Esses dejetos são desviados para a parte da cidade onde é alagada e por ter piso firme é preferida para o banho da garotada e mesmo dos adultos. Esta água estancada por um período de dois a três meses é fonte de disseminação de um vasto número de doenças infecto-contagiosas.

Além do saneamento básico necessitar-seiam de campanhas de esclarecimento sanitário, realizadas por educadores, assistentes sociais e visitadores, além de pessoal para-médico treinados para a finalidade, pois, somente a presença do médico, pouco poderá contribuir para a melhoria das condições de saúde, uma vez que esta depende, fundamentalmente, das condições ambientais e do padrão sócio-econômico cultural e nutricional da população.

\section{SUMMARY}

The authors make a social, parasitic and sanitary study in the city of Nova Olinda do Norte. State of Amazonas-Brazil. They give special attetion to the mechanisms of transmission in two classes of parasitic disease: helminthiasis and protozoosis. They discuss and compare the results with other works made in several cities in the Amazon area.

\section{BIBLIOGRAFIA CITADA}

Causey, O. R.; Costa, O. \& Causey, C. E.

1947 - Incidência de Parasitos intestinais do homem em Belém, Pará e Vizinhanças. Rev. do Serv. Esp. Saúde Pública, 1(2): 221-233.

Costa, O. R.

1947 — Incidência de parasitos intestinais em quatro cidades da Amazônia. Rev. Serv. Esp. Saúde Pública, $1(2)$ : 203-219.

Faust, E. C.; Sawitz, W.; TOBIE, J.; OdON, V.;

PERES, C. \& Lincicome, D. R.

1939 - Comparative efficiency of various tecnics for the diagnosis of protozoa and helminths in fezes. J. Parasit., $25: 241-262$.

Moraes, M. A. P.

1959 - Inquérito sobre parasitos intestinais na cidade de Codajás, Estado do Amazonas. Brasil Médico, 16(7) : 488-491.

OLIVEIRA, W. R.

1959 - Contribuição ao estudo coprológico na cidade de Manaus. Brasil Médico, 73(7/28): 123-125.

Pinheiro, M. F. S.; Vasconcelos, J. C. \& Wendell, D. E. 1976 - Contribuição ao estudo de parasitos intestinais em dois bairros de Manaus, Amazonas. Acta Amazonica, 6(1): 67-73.

(Aceito para publicação em $12 / 12 / 77$ ) 